\title{
Editorial
}

\section{RETHINKING (TRANS)NATIONAL POLITICS AND BELONGING}

The ongoing transnational experiences of Latino/as continue to impact on our understanding of such issues as nationalism, belonging, social movements, the changing political culture and immigration policies, and the emergence of new identities in this era of globalization.

In this issue, we publish an essay by Amalia Pallares on the changing meanings of nationalism in this transnational age. As her article suggests, these meanings are no longer tied exclusively to national territories, such as Ecuador, Mexico, Colombia, but rather to immigrants' increasing (trans) national forms if not of patriotism, certainly of affirming belonging in their new society. Similarly, in her article, Kara Zugman documents the extent to which social movements in the US context too are increasingly being influenced by the new grassroots political culture developing across the border. Her article details the cross-border impact of the Zapatista movement and ideas of political organizing on efforts to achieve social justice and improve the lives of Latinos in Los Angeles.

In addition to these articles documenting the impact of transnationalism in our understanding of political meanings, respectively, of immigrants' incorporation, belonging and social action, we publish a special section edited and introduced by Holly Ackerman, Damian Fernández and Maria Domínguez, on the 1994 Cuban Balseros. The articles in this section raise such issues as the state's deterritorialized and authoritarian reach, and the changing nature of US immigration policies towards Cubans as well as examining the decline of mechanisms to ensure that rights - whether those of citizens or, as in the case of Cuban Balseros, those of refugees and undocumented immigrants - are actually upheld.

Once again, Silvio Torres-Saillant provides us with a thought-provoking section of Páginas Recuperadas - pages recovered from the historical past of Latinos/as in the US. In keeping with our special feature focus on the Cuban experience, Torres-Saillant provides us with the contextual background and story of Evangelina Cisneros, characterizing her literary contribution as an "analytical provocation for scholars interested in mining its potential for dramatizing the problems of the location of US Cuban writing, the complex texture of US-Cuban relations, and the unique character of CubanAmerican identity vis-à-vis the other subsections of the Latino population."

Ultimately, the articles in this issue, including the essays and personal recollections on the Cuban balseros in the Vivencias section enable us to pursue broader issues pertaining to both the realities of forced departure 
倠 latino studies - 3:3

from one's homeland and the experiences of entering a new state. The issue underscores the importance of better understanding the changing conditions and possibilities for residence and participation in the new society. As we have recently seen through the experience of the internally displaced refugees, now dealing with the devastating tragedy of Hurricane Katrina and its political aftermath, we must pose deeper questions about rights and the meaning of belonging, not only for those who arrive and eventually settle in this country from abroad, but also, for all who live in US society, regardless of their status as citizens, exiles, refugees or immigrants.

Saludos!

Suzanne Oboler University of Illinois at Chicago, IL

Latino Studies (2005) 3, 323-324. doi:10.1057/palgrave.lst.8600168 